Proc. Indian Acad. Sci. (Chem. Sci.), Vol. 107, No. 2, April 1995, pp. 133-141.

(C) Printed in India.

\title{
Kinetics and mechanism of the oxidation of diols by pyridinium hydrobromide perbromide
}

\author{
DIPTI MATHUR, PRADEEP K SHARMA and KALYAN K BANERJ ${ }^{*}$
}

Department of Chemistry, J N V University, Jodhpur 342005, India

MS received 28 April 1994; revised 26 July 1994

\begin{abstract}
Kinetics of oxidation of five vicinal, four non-vicinal diols, and one of their monoethers by pyridinium hydrobromide perbromide (PHPB) have been studied. The vicinal diols yield products arising out of the glycol bond fission while the other diols yield hydroxycarbonyl compounds. The reaction is first order with respect to PHPB. Michaelis-Menten type kinetics are observed wih respect to the diol. There is no effect of added pyridinium bromide on the reaction. The oxidation of $\left[1,1,2,2-{ }^{2} \mathrm{H}_{4}\right]$ ethanediol shows the absence of a primary kinetic isotope effect. The values of solvent isotope effect, $k\left(\mathrm{H}_{2} \mathrm{O}\right) / k\left(\mathrm{D}_{2} \mathrm{O}\right)$, at $313 \mathrm{~K}$, for the oxidation of ethanediol, propane-1,3-diol and 3-methoxybutan-1-ol are 4.71, 2.17 and $2 \cdot 23$ respectively. A mechanism involving glycol-bond fission has been proposed for the oxidation of the vicinal diols. The other diols are oxidised by a hydride-transfer mechanism as they are monohydric alcohols.
\end{abstract}

Keywords. Diols; pyridinium hydrobromide perbromide; kinetics; mechanism; oxidation.

\section{Introduction}

Pyridinium hydrobromide perbromide (PHPB) is a well-known brominating and dehydrogenating agent and its use in synthetic organic chemistry is well documented (Fieser and Fieser 1967; Heasley et al 1988). We have been interested in the kinetics and mechanism of the oxidation by PHPB and have reported the oxidation of alcohols (Mathur et al 1993), lower oxyacids of phosphorus (Varshney et al 1992), and aliphatic aldehydes (Devi et al 1993) by PHPB. However, several oxidations of monohydric and polyhydric alcohols are known to follow different mechanistic pathways, e.g. oxidations by lead (IV) (Bunton 1966), periodic acid (Duke 1947), acid permanganate (Bhatia and Banerji 1983) and bromamine-B (Mathur and Banerji 1987). Therefore, we have studied the oxidation of several diols by PHPB in aqueous acetic acid solution. The mechanistic aspects are discussed.

\section{Experimental}

\subsection{Materials}

The diols were commercial products and were distilled under reduced pressure before use. $\left[1,1,2,2{ }^{2} \mathrm{H}_{4}\right]$ ethanediol was prepared by the reduction of diethyl oxalate with

\footnotetext{
* For correspondence
} 
lithium aluminium deuteride (Kemp and Waters 1963). Its isotopic purity, determined by its NMR spectrum, was $90 \pm 4 \%$. PHPB was prepared by the reported method (Fieser and Fieser 1967) and its purity checked by an iodometric method.

\subsection{Product analysis}

The product analyses were carried under kinetic conditions. In a typical experiment ethanediol $(6.2 \mathrm{~g}, 0.1 \mathrm{~mol})$ and PHPB $(6.3 \mathrm{~g}, 0.02 \mathrm{~mol})$ were dissolved in $100 \mathrm{ml}$ of $1: 1$ $(\mathrm{v} / \mathrm{v})$ acetic acid-water and was kept in the dark for about $12 \mathrm{~h}$ to ensure completion of the reaction. The solution was then treated with an excess $\left(200 \mathrm{~cm}^{3}\right)$ of a saturated solution of 2,4-dinitrophenylhydrazine in $2 \mathrm{~mol} \mathrm{dm}^{-3} \mathrm{HCl}$ and kept in a refrigerator for about $15 \mathrm{~h}$. The precipitated 2,4-dinitrophenylhydrazone (DNP) was filtered off, weighed, recrystallized from ethanol, and weighed again. The product was identical (m.p. and mixed m.p.) with an authentic sample of the DNP of formaldehyde. The yield of DNP before and after recrystallization was $7.4 \mathrm{~g}(88 \%)$ and $6.8 \mathrm{~g}(81 \%)$. A similar experiment with propane-1,3-diol yielded DNP of 3-hydroxypropanal in $73 \%$ yield after recrystallization.

\subsection{Kinetic measurements}

The pseudo-first-order conditions were attained by keeping an excess ( $\times 15$ or greater) of the diol over PHPB. The solvent was $1: 1(\mathrm{v} / \mathrm{v})$ acetic acid-water, unless mentioned otherwise. The reactions were carried out in flasks blackened from the outside to avoid any photochemical reactions and were followed by monitoring the decrease in the [PHPB] at $358 \mathrm{~nm}$ for up to $70 \%$ reaction. The pseudo-first-order rate constants, $k_{\text {obs }}$, were evaluated from the linear least-squares plots of $\log$ [PHPB] against time. Duplicate kinetic runs showed that the rate constants are reproducible to within $\pm 3 \%$. Simple and multivariate linear regression analyses were carried out by the least-squares method.

\section{Results}

\subsection{Stoichiometry}

The oxidation of vicinal diols by PHPB yields products arising from the glycol-bond fission, i.e. rupture of the bond between the carbon atoms bearing the hydroxy groups, while the other diols give products of simple oxidation of one of the hydroxy groups. Analyses of products indicate the overall reactions below.

$$
\begin{aligned}
& \begin{array}{l}
\mathrm{R}_{2}-\underset{\mathrm{C}}{\mathrm{C}}-\mathrm{OH} \\
\mathrm{R}_{2}-\mathrm{C}-\mathrm{OH}
\end{array}+\mathrm{PyH}^{+} \mathrm{Br}_{3 \uparrow}^{-} \rightarrow 2 \mathrm{R}_{2} \mathrm{CO}+2 \mathrm{HBr}+\mathrm{PyH}^{+} \mathrm{Br}^{-} \\
& \mathrm{HO}-\mathrm{CH}_{2}-\left(\mathrm{CH}_{2}\right)_{n}-\mathrm{CH}_{2} \mathrm{OH}+\mathrm{PyH}^{+} \mathrm{Br}_{3}^{-} \rightarrow \\
& \mathrm{HO}-\mathrm{CH}_{2}-\left(\mathrm{CH}_{2}\right)_{n}-\mathrm{CHO}+\mathrm{PyH}^{+} \mathrm{Br}^{-}+2 \mathrm{HBr}
\end{aligned}
$$

\subsection{Rate laws}

The reactions were found to be first-order with respect to PHPB. Individual kinetic runs were strictly first-order in PHPB. Further, the first-order rate coefficients did not vary with the initial concentration of PHPB. The order with respect to the diol is less than one (table 1 ). A plot of $1 / k_{\text {obs }}$ versus $1 /[$ diol $]$ is linear with an intercept on 
Table 1. Rate constants for the oxidation of ethanediol and propane-1,3-diol at $313 \mathrm{~K}$.

\begin{tabular}{|c|c|c|c|c|}
\hline \multirow{2}{*}{$\begin{array}{l}10^{3}[\mathrm{PHPB}] \\
\left(\mathrm{mol} \mathrm{dm}^{-3}\right)\end{array}$} & \multicolumn{2}{|c|}{$[$ Diol $]\left(\mathrm{mol} \mathrm{dm}^{-3}\right)$} & \multicolumn{2}{|c|}{$10^{5} k_{o b s}\left(S^{-1}\right)$} \\
\hline & Ethanediol & Propane-1,3-diol & Ethanediol & Propane-1,3-diol \\
\hline 1.0 & 0.10 & 0.04 & 8.64 & 2.53 \\
\hline 10 & 0.17 & 0.06 & $12 \cdot 4$ & 3.56 \\
\hline 10 & 0.25 & 0.08 & 15.5 & 4.46 \\
\hline 10 & 0.36 & 0.10 & 18.5 & 5.25 \\
\hline 1.0 & 0.45 & 0.25 & $20-2$ & $9 \cdot 19$ \\
\hline 10 & 0.55 & 0.34 & 21.8 & 10.6 \\
\hline 1.0 & 0.67 & 0.44 & $23 \cdot 2$ & 11.7 \\
\hline 2.0 & 0.45 & 0.34 & $20 \cdot 3$ & 10.2 \\
\hline 4.0 & 0.45 & 0.34 & 19.8 & $10 \cdot 1$ \\
\hline 60 & 0.45 & 0.34 & $20 \cdot 1$ & 10.3 \\
\hline 8.0 & 0.45 & 0.34 & $19 \cdot 9$ & 10.5 \\
\hline
\end{tabular}

the rate ordinate. Thus Michaelis-Menten type kinetics are observed with respect to the diols. This leads to the postulation of the following overall mechanism (3) and (4) and rate law (5).

$$
\begin{aligned}
& \text { Diol }+ \text { PHPB } \stackrel{K}{\rightleftharpoons}[\text { complex }], \\
& {[\text { complex }] \stackrel{k_{2}}{\rightarrow} \text { products, }} \\
& \text { Rate }=k_{2} K[\text { diol }][\mathrm{PHPB}] /(1+K[\text { diol }]) .
\end{aligned}
$$

The dependence on the concentration of the diol was studied at different temperatures and the values of $K$ and $k_{2}$ were calculated from the double reciprocal plots. The thermodynamic parameters of the complex formation and the activation parameters of the decomposition of the complexes were calculated from the values of $K$ and $k_{2}$ respectively at different temperatures (tables 2 and 3 ).

\subsection{Isotope effects}

To ascertain the importance of the cleavage of the $\alpha-\mathrm{C}-\mathrm{H}$ bond in the rate-determining step, the oxidation of $\left(1,1,2,2-{ }^{2} \mathrm{H}_{4}\right)$ ethanediol was studied. The results showed the absence of a primary kinetic isotope effect.

The rates of oxidation of ethanediol, propane-1, 3-diol, and 3-methoxybutan-1-ol were obtained in deuterium oxide (overall $95 \% \mathrm{D}_{2} \mathrm{O}$ ). This set of experiments was carried out in aqueous solutions. The values of $k\left(\mathrm{H}_{2} \mathrm{O}\right) / k\left(\mathrm{D}_{2} \mathrm{O}\right)$, at $313 \mathrm{~K}$, are $4 \cdot 71,2 \cdot 17$ and $2 \cdot 23$ respectively.

\subsection{Effect of pyridinium bromide}

The rates of oxidation were not affected by an addition of pyridinium bromide (up to $0.02 \mathrm{~mol} \mathrm{dm}^{-3}$ ). 
Table 2. Formation constants and thermodynamic parameters of the diol-PH PB complexes.

\begin{tabular}{|c|c|c|c|c|c|c|c|}
\hline \multirow[b]{2}{*}{ Diol } & \multicolumn{4}{|c|}{$K\left(\mathrm{dm}^{3} \mathrm{~mol}^{-1}\right)$ at temp. $(\mathrm{K})=$} & \multirow{2}{*}{$\begin{array}{c}\Delta H \\
\left(\mathrm{~kJ} \mathrm{~mol}^{-1}\right)\end{array}$} & \multirow{2}{*}{$\begin{array}{c}\Delta S \\
\left(\mathrm{~J} \mathrm{~mol}^{-1} \mathrm{~K}^{-1}\right)\end{array}$} & \multirow{2}{*}{$\begin{array}{c}\Delta G \\
\left(\mathrm{~kJ} \mathrm{~mol}^{-1}\right)\end{array}$} \\
\hline & 293 & 303 & 313 & 323 & & & \\
\hline $\begin{array}{l}\text { Ethane- } \\
\text { diol }\end{array}$ & $6 \cdot 52$ & $4 \cdot 78$ & 3.55 & $2 \cdot 58$ & $-24 \cdot 1 \pm 0.4$ & $-67 \pm 1$ & $-4 \cdot 3 \pm 0.3$ \\
\hline $\begin{array}{l}\text { Propane- } \\
\text { 1,2-diol }\end{array}$ & $7 \cdot 21$ & $5 \cdot 48$ & $4 \cdot 20$ & $3 \cdot 12$ & $-21 \cdot 8 \pm 0.5$ & $-58 \pm 2$ & $-4.5 \pm 0.4$ \\
\hline $\begin{array}{l}\text { Butane- } \\
\text { 2,3-diol }\end{array}$ & 6.93 & $4 \cdot 87$ & 3.42 & $2 \cdot 38$ & $-28.0 \pm 0.5$ & $-80 \pm 2$ & $-4 \cdot 3 \pm 0.4$ \\
\hline $\begin{array}{l}\text { Butane- } \\
\text { 1,2-diol }\end{array}$ & 6.41 & $4 \cdot 50$ & $3 \cdot 30$ & $2 \cdot 30$ & $-26.6 \pm 0.5$ & $-76 \pm 2$ & $-4 \cdot 2 \pm 0.3$ \\
\hline Pinacol & 7.03 & $5 \cdot 11$ & 3.82 & 2.79 & $-24 \cdot 1 \pm 0.4$ & $-66 \pm 1$ & $-4 \cdot 4 \pm 0.3$ \\
\hline $\begin{array}{l}\text { Propane- } \\
\text { 1,3-diol }\end{array}$ & $8 \cdot 75$ & 5.90 & 4.00 & $2 \cdot 77$ & $-30 \cdot 2 \pm 0.4$ & $-85 \pm 3$ & $-4.9 \pm 0.4$ \\
\hline $\begin{array}{l}\text { Butane- } \\
\text { 1,3-diol }\end{array}$ & $9 \cdot 21$ & 6.00 & 3.89 & $2 \cdot 60$ & $-33 \cdot 2 \pm 0 \cdot 3$ & $-95 \pm 2$ & $-5 \cdot 0 \pm 0.5$ \\
\hline $\begin{array}{l}\text { Butane- } \\
\text { 1,4-diol }\end{array}$ & $8 \cdot 32$ & $5 \cdot 12$ & $3 \cdot 15$ & 1.92 & $-38.4 \pm 0.6$ & $-114 \pm 3$ & $-4.6 \pm 0.5$ \\
\hline $\begin{array}{l}\text { Pentane- } \\
\text { 1,5-diol }\end{array}$ & $9 \cdot 56$ & $5 \cdot 80$ & $3 \cdot 50$ & $2 \cdot 11$ & $-39.6 \pm 0.6$ & $-117 \pm 4$ & $-5 \cdot 0 \pm 0.5$ \\
\hline $\begin{array}{l}\text { 3-Methoxy- } \\
\text { butan-1-ol }\end{array}$ & $10 \cdot 4$ & $7 \cdot 31$ & $5 \cdot 20$ & $3 \cdot 50$ & $-28 \cdot 3 \pm 0 \cdot 8$ & $-78 \pm 3$ & $-5.4 \pm 0.6$ \\
\hline $\begin{array}{l}\text { 2-Methoxy- } \\
\text { ethanol }\end{array}$ & 10.2 & $6 \cdot 75$ & $4 \cdot 80$ & $3 \cdot 22$ & $-32 \cdot 4 \pm 0.6$ & $-83 \pm 2$ & $-7 \cdot 7 \pm 0.4$ \\
\hline
\end{tabular}

'Data from Mathur et al (1993)

\subsection{Effect of solvent composition}

The rate of oxidation was determined in solvents containing different amounts of acetic acid and water. It was observed that the rate increased with an increase in the amount of water in the solvent.

To determine whether the changes in solvent composition are affecting the formation constant, $K$, and/or the rate constant of the decomposition, $k_{2}$, the dependence on diol concentration was studied in solvents of different compositions. Results showed that the effect of solvent is primarily on the rate constant for the decomposition of the complex, $k_{2}$. The formation constant, $K$, is practically independent of solvent composition (table 4).

\section{Discussion}

In solution, PHPB may undergo the following reactions (6) and (7).

$$
\begin{aligned}
& \mathrm{PyH}^{+} \mathrm{Br}_{3}^{-} \rightleftarrows \mathrm{Br}_{2}+\mathrm{PyH}^{+} \mathrm{Br}^{-}, \\
& \mathrm{PyH}^{+} \mathrm{Br}_{3}{ }^{-} \rightleftarrows \mathrm{Br}_{3}{ }^{-}+\mathrm{PyH}^{+} .
\end{aligned}
$$


Table 3. Rate constants and activation parameters of the decomposition of diol-PHPB complexes.

\begin{tabular}{|c|c|c|c|c|c|c|c|}
\hline \multirow[b]{2}{*}{ Diol } & \multicolumn{4}{|c|}{$10^{5} k_{2}\left(s^{-1}\right)$ at temp. $(K)=$} & \multirow{2}{*}{$\begin{array}{c}\Delta H^{*} \\
\left(\mathrm{~kJ} \mathrm{~mol}^{-1}\right)\end{array}$} & \multirow{2}{*}{$\underset{\left(\mathrm{J} \mathrm{mol}^{-1} \mathrm{~K}^{-1}\right)}{\Delta S^{*}}$} & \multirow{2}{*}{$\begin{array}{c}\Delta G^{*} \\
\left(\mathrm{~kJ} \mathrm{~mol}^{-1}\right)\end{array}$} \\
\hline & 293 & 303 & 313 & 323 & & & \\
\hline $\begin{array}{l}\text { Ethane- } \\
\text { diol }\end{array}$ & 0.93 & $1 \cdot 75$ & $3 \cdot 30$ & $6 \cdot 20$ & $47 \cdot 2 \pm 0 \cdot 7$ & $-181 \pm 2$ & $101 \pm 0.5$ \\
\hline $\begin{array}{l}\text { Propane- } \\
\text { 1,2-diol }\end{array}$ & $1 \cdot 36$ & 2.44 & $4 \cdot 52$ & $8 \cdot 12$ & $44.5 \pm 0 \cdot 5$ & $-187 \pm 2$ & $100 \pm 0.6$ \\
\hline $\begin{array}{l}\text { Butane- } \\
\text { 2,3-diol }\end{array}$ & 1.88 & $3 \cdot 33$ & 5.88 & $10 \cdot 5$ & $42.5 \pm 0.7$ & $-191 \pm 3$ & $99.3 \pm 0.6$ \\
\hline $\begin{array}{l}\text { Butane- } \\
\text { 1,2-diol }\end{array}$ & 3.60 & $6 \cdot 16$ & $10-5$ & 180 & $39.6 \pm 0.6$ & $-195 \pm 2$ & $97.7 \pm 0.5$ \\
\hline Pinacol & 3.82 & $6 \cdot 36$ & $10-8$ & 18.6 & $39-0 \pm 0.9$ & $-197 \pm 3$ & $97.6 \pm 0.7$ \\
\hline $\begin{array}{l}\text { Propane- } \\
\text { 1,3-diol }\end{array}$ & 2.95 & 7.40 & $18 \cdot 4$ & 46.4 & $70-0 \pm 0-9$ & $-93 \pm 3$ & $97 \cdot 7 \pm 0 \cdot 7$ \\
\hline $\begin{array}{l}\text { Butane- } \\
\text { 1,3-diol }\end{array}$ & 4.90 & 11.6 & $25 \cdot 2$ & $63 \cdot 5$ & $64 \cdot 0 \pm 1 \cdot 7$ & $-110 \pm 5$ & $96 \cdot 5 \pm 1 \cdot 3$ \\
\hline $\begin{array}{l}\text { Butane- } \\
\text { 1,4-diol }\end{array}$ & $4 \cdot 20$ & $10-5$ & $23 \cdot 6$ & $56 \cdot 8$ & $65 \cdot 3 \pm 0.9$ & $-106 \pm 3$ & $96 \cdot 9 \pm 0.7$ \\
\hline $\begin{array}{l}\text { Pentane- } \\
\text { 1,5-diol }\end{array}$ & $5 \cdot 12$ & 12.6 & $29 \cdot 0$ & $64 \cdot 8$ & $63 \cdot 9 \pm 0.9$ & $-109 \pm 4$ & $96.4 \pm 0.2$ \\
\hline $\begin{array}{l}\text { 3-Methoxy- } \\
\text { butan-1-ol }\end{array}$ & 5.80 & $13 \cdot 4$ & $28 \cdot 3$ & $70-0$ & $62 \cdot 1 \pm 1 \cdot 7$ & $-115 \pm 3$ & $96 \cdot 2 \pm 1 \cdot 3$ \\
\hline $\begin{array}{l}\text { 2-Methoxy- } \\
\text { ethanol }\end{array}$ & 3.44 & 8.82 & $20-6$ & 500 & $67 \cdot 3 \pm 0.7$ & $-101 \pm 2$ & $97.3 \pm 0.6$ \\
\hline
\end{tabular}

-Data from Mathur et al (1993)

The probable oxidizing species in a solution of PHPB are, therefore, PHPB itself, tribromide ion and molecular bromine. However, strict first-order dependence on PHPB and the absence of any effect of pyridinium bromide on the rate of reaction ruled out both bromide and tribromide ion as the reactive oxidizing species. Thus the most probable oxidizing species is PHPB itself.

The increase in the values of $k_{2}$ with an increase in the polarity of the medium suggests that in the rate-determining step, the transition state is more polar than the reactant. A plot of $\log k_{2}$ against the inverse of relative permittivity is nonlinear. The solvent effect was analysed using the Grunwald-Winstein (Falnberg and Winstein 1956) equation

$$
\log k_{2}=\log k_{0}+m Y
$$

The plot of $\log k_{2}$ against $Y$ was linear $\left(r^{2}=0.9978\right)$ with $m=0.54 \pm 0.01$. The value of $m$ points to a transition state which is more polar than the reactant.

The diverse nature of the products formed in the oxidation of vicinal diols and other diols suggests that these compounds follow different mechanistic pathways. This is further supported by the two linear plots obtained between $\log$ (rate) at $293 \mathrm{~K}$ and at $323 \mathrm{~K}$, one for the vicinal diols and another for the rest (figure 1). 
Table 4. Dependence of $k_{\mathrm{obs}}$ on the concentration of ethanediol in solvents of different compositions.

$[\mathrm{PHPB}]=0.001 \mathrm{~mol} \mathrm{dm}^{-3}, T=313 \mathrm{~K}$

\begin{tabular}{|c|c|c|c|c|c|}
\hline \multirow{2}{*}{$\frac{[\text { Diol }]}{\left(\mathrm{mol} \mathrm{dm}^{-3}\right)}$} & \multicolumn{5}{|c|}{$10^{6} k_{\mathrm{obs}}\left(\mathrm{s}^{-1}\right)[\mathrm{at} \% \mathrm{AcOH}(\mathrm{v} / \mathrm{v})]$} \\
\hline & 25 & 40 & 50 & 60 & 72 \\
\hline $0-01$ & 28.0 & 14.4 & 8.64 & $5 \cdot 20$ & $2 \cdot 82$ \\
\hline 0.17 & $40 \cdot 5$ & $20 \cdot 7$ & $12 \cdot 4$ & 7.47 & 4.06 \\
\hline 0.25 & $50 \cdot 1$ & 26.0 & $15 \cdot 5$ & $9 \cdot 36$ & 5.03 \\
\hline 0.36 & $60 \cdot 7$ & 30.5 & $18 \cdot 5$ & $11 \cdot 2$ & 6.08 \\
\hline 0.45 & 66.5 & 33.8 & $20 \cdot 2$ & $12 \cdot 3$ & $6 \cdot 70$ \\
\hline 0.55 & $71 \cdot 5$ & $36 \cdot 3$ & 21.8 & $13 \cdot 3-$ & $7 \cdot 21$ \\
\hline$K / \mathrm{dm}^{3} \mathrm{~mol}^{-1}$ & 3.46 & 3.60 & 3.55 & 3.52 & 3.40 \\
\hline $10^{5} k_{2} / \mathrm{s}^{-1}$ & $10 \cdot 9$ & $5 \cdot 45$ & $3 \cdot 30$ & $2 \cdot 00$ & $1 \cdot 10$ \\
\hline
\end{tabular}

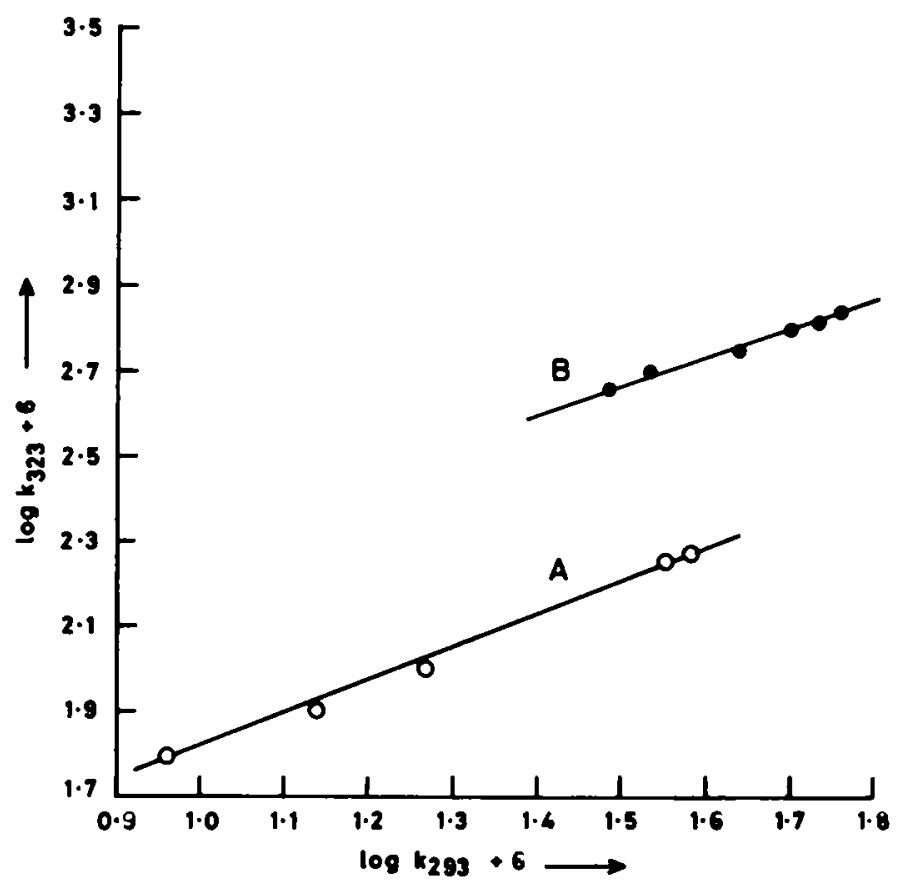

Figure 1. Isokinetic relationship in the oxidation of vicinal and other diols by PHPB. A-vicinal diols, B-other diols.

\subsection{Oxidation of vicinal diols}

The linear correlation between $\log ($ rate) at $293 \mathrm{~K}$ and $323 \mathrm{~K}$ for the oxidation $(r=0.9996$; slope $=0.7904 \pm 0.0133$ ) shows that an isokinetic relationship exists in the oxidation of vicinal diols by PHPB (Exner 1973). The value of the isokinetic temperature is $528 \pm 26 \mathrm{~K}$. An isokinetic relationship is a necessary condition for the validity of 
linear-free energy relationships. It also implies that all the diols are oxidized by the similar mechanism.

The absence of a primary kinetic isotope effect confirms that the $\alpha-\mathrm{C}-\mathrm{H}$ bond is not cleaved in the rate-determining step. In contrast, substantial primary kinetic isotope effect was observed in the oxidations of ethanol by PHPB (Mathur et al 1993). Thus it seems that the oxidation of monohydric alcohols and vicinal diols follows different mechanisms.

Active hydrogens like those present in hydroxyl and carboxyl groups undergo rapid exchange in deuterium oxide. If the cleavage of the $\mathrm{O}-\mathrm{H}$ bond is involved in the rate-determining step, the $\mathrm{O}-\mathrm{H} / \mathrm{O}-\mathrm{D}$ isotope effect comes into play. In view of the observed value of solvent isotope effect, an $\mathrm{O}-\mathrm{H}$ bond cleavage in the rate-determini1.g step is indicated. The large magnitude of solvent isotope effect, observed in the oxidation of ethanediol, suggests that both the hydroxy groups are involved in the rate-determining step. The magnitude of the negative entropy of activation is almost double in the oxidation of vicinal diols as compared to that of the other compounds (table 3). This points to a more rigid transition state in the oxidation of the vicinal diols. The only mode of oxidation available for pinacol is the fission of the bonds between carbinol carbon atoms. That the other vicinal diols follow this mechanism is confirmed by the isolation of products formed by the $\mathrm{C}-\mathrm{C}$ bond fission and the isokinetic relationship.

From the rate-law (5), it is apparent that an intermediate complex is formed in a rapid pre-equilibrium. With the present data it is not possible to state definitely the nature of the intermediate complex. Formation of a hypobromite ester, as given below, as an intermediate is unlikely in view of the absence of any effect of pyridinium bromide.

$$
\mathbf{R O H}+\mathrm{PyH}^{+} \mathrm{Br}_{\mathbf{3}}^{-} \rightleftarrows \mathbf{R}-\mathrm{O}-\mathrm{Br}+\mathrm{PyH}^{+} \mathrm{Br}^{-}+\mathrm{Br}^{-}
$$

Heasley et al (1988) have postulated the formation of an intermediate $\pi$-complex in the reaction of alkenes with PHPB. A similar complex may be formed by the interaction between the non-bonded pairs of hydroxy oxygens and PHPB. The formation of a moderately stable intermediate is supported by the observed thermodynamic parameters (table 3). The complex formation is favoured by the enthalpy term but there is a loss of entropy indicating a rigid structure.

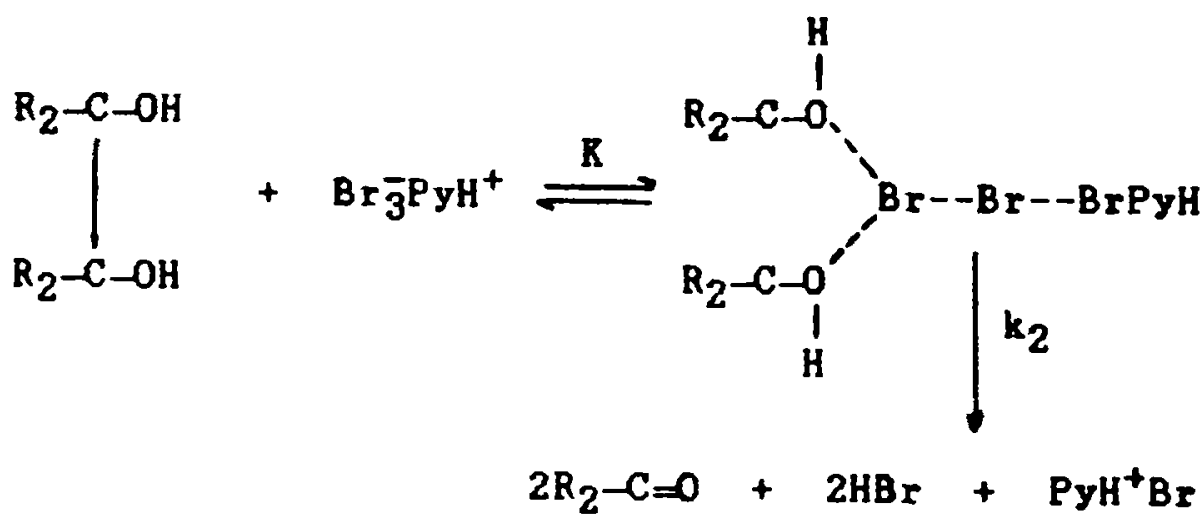

Scheme 1. 
Table 5. Reaction constants of the oxidation of vicinal diols by PHPB.

\begin{tabular}{ccccc}
\hline$T / \mathrm{K}$ & $\rho_{\mathrm{I}}$ & $\delta$ & $R^{2}$ & $s d$ \\
\hline 293 & $-0.97 \pm 0.05$ & $-1.49 \pm 0.03$ & 0.9996 & 0.007 \\
303 & $-0.84 \pm 0.02$ & $-1.40 \pm 0.01$ & 0.9999 & 0.003 \\
313 & $-0.76 \pm 0.05$ & $-1.29 \pm 0.03$ & 0.9995 & 0.007 \\
323 & $-0.71 \pm 0.04$ & $-1.19 \pm 0.02$ & 0.9996 & 0.006
\end{tabular}
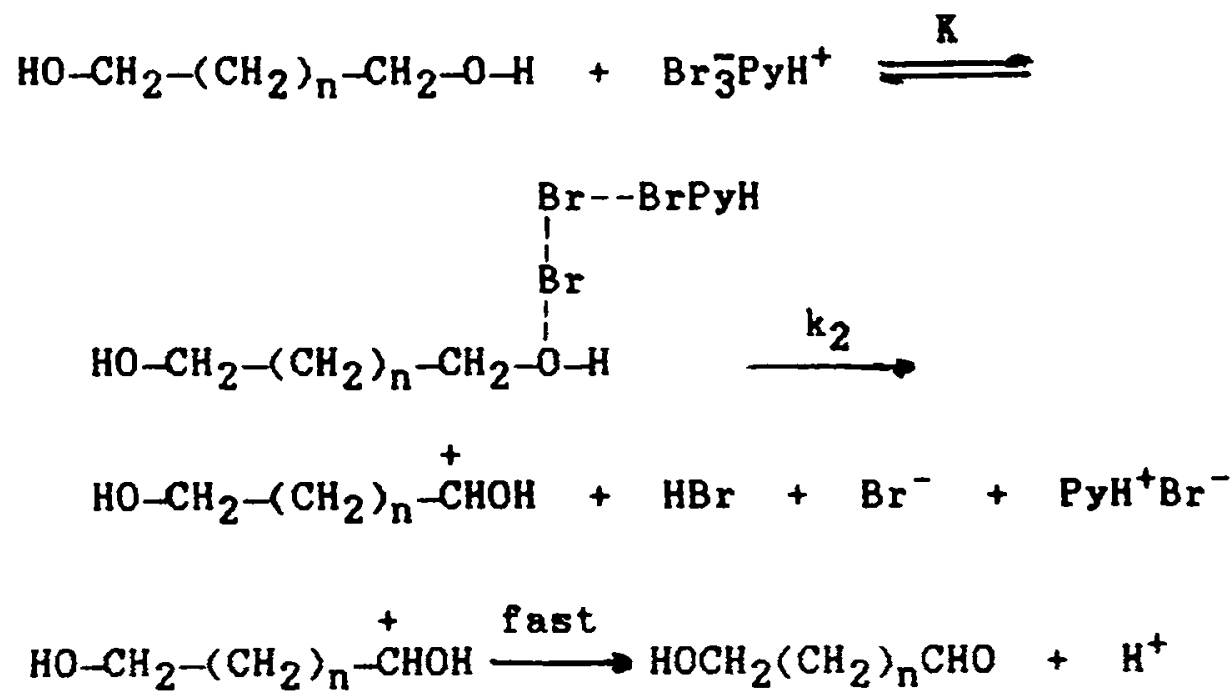

\section{Scheme 2.}

The mechanism depicted in scheme 1 accounts for the experimental results.

4.1a Correlation of structure and reactivity: A perusal of the data in tables 2 and 3 showed that the formation constants of the PBPB-diol complexes are not sensitive to the structure of the diol. However, the rate constants of the decomposition show considerable variation. The rates of decomposition were, therefore, subjected to correlation analyses.

The rates of decomposition of the complexes failed to show satisfactory correlation with either the polar or steric substituent constants (Johnson 1987). Therefore, the rates were analysed in terms of the dual substituent-parameter (DSP) equation (9) of Pavelich and Taft (1957)

$$
\log k=\rho_{I} \Sigma \sigma_{I}+\delta \Sigma E_{s}+\log k_{0}
$$

The results recorded in table 5 , show that the rates exhibited an excellent correlation with polar and steric substituent constants. Though the number of compounds (five) is rather small for a correlation analysis by a DSP equation, the correlations are excellent and the results can be used qualitatively. 
The values of the reaction constants support the proposed mechanism. The small nagative polar reaction constant accords with the net flow of electrons towards the oxidant. The negative steric reaction constant implies a steric acceleration of the reaction. This is probably due to increase in the steric relief on going from tetragonal $\left(s p^{3}\right)$ carbon atoms to trigonal $\left(s p^{2}\right)$ ones, with increasing substitution at the carbon atoms.

\subsection{Oxidation of other diols}

The linear correlation between $\log k$ at $293 \mathrm{~K}$ and $323 \mathrm{~K}(r=0.9986$, slope $=0.6235 \pm$ 0.0167) for the oxidation of four non-vicinal diols, 3-methoxybutan-1-ol, and 2methoxyethanol shows that all the compounds are oxidized by the same mechanism (Exner 1973). The value of the isokinetic temperature is $389 \pm 5 \mathrm{~K}$. 3-methoxybutan-1ol and 2-methoxyethanol are typical monohydric alcohols and, therefore, it is highly likely that these diols are oxidized by a mechanism similar to that operative for monohydric alcohols. The oxidation of ethanol (Mathur et al 1993) exhibited a substantial kinetic isotope effect confirming the cleavage of the $\alpha-\mathrm{C}-\mathrm{H}$ bond in the ratedetermining step. Therefore, a mechanism, similar to one proposed earlier (Mathur et al 1993) for monohydric alcohols, accounts for the experimental results obtained in the oxidation of non-vicinal diols (scheme 2).

\section{Acknowledgements}

Thanks are due to University Grants Commission and the Council of Scientific and Industrial Research, New Delhi, India for financial support.

\section{References}

Bhatia I and Banerji K K 1983 J. Chem. Soc., Perkin Trans. 21577

Bunton C A 1966 Oxidation in organic chemistry (ed.) K B Wiberg (New York: Academic Press) chap. VI

Devi J, Kothari S and Banerji K K 1993 J. Chem. Res. (S) (M)400 2680

Duke F R 1947 J. Am. Chem. Soc. 693054

Exner O 1973 Prog. Phys. Org. Chem 10411

Falnberg A H and Winstein S $1956 \mathrm{~J}$. Am. Chem. Soc. 782770

Fieser $L$ and Fieser $M 1967$ Reagents for organic synthesis (New York: Wiley) vol. 1

Heasley V L, Louie T J, Luttrull D K, Miller M D, Moore H B, Nogales D F, Sauerbrey A M, Shevel A B, Stanley M S, Shellhamer D F and Heasley G E 1988 J. Org. Chem. 532199

Johnson C D 1987 The Hammett equation (Cambridge: University Press) p. 54

Kemp T J and Waters W A 1963 Proc. R. Soc. London A274 480

Mathur A and Banerji K K 1987 J. Chem. Soc., Perkin Trans. 21645

Mathur D, Sharma P K and Banerji K K 1993 J. Chem. Soc., Perkin Trans 2205

Pavelich W A and Taft R W 1957 J. Am. Chem. Soc. 794935

Varshney S, Sharma P K and Banerji K K 1992 Proc. Indian Acad. Sci. (Chem. Sci.) 104603 